ment, even though our increased knowledge robs us of some of the credit which we had fondly attributed to our own efforts; for the future of Medicine is at this moment more bright than it has ever shone before. To quote the last words of Dr. Todd: "There never was a period when a candid and ample reconsideration of general pathology promised more fruitful results than the present. Our widely extended acquaintance with anatomy and physiology - the greatly enlarged security of the basis on which our knowledge of function rests-the much increased accumulation of facts of clinical history - all afford most important data for new inductions." That exhortation, gentlemen, (continued the lecturer,) calls upon the whole rising race of medical men; it is addressed to every one of you, for every one can help in the great work of accumulating and tab lating clinical facts. We must all of us be discoverers; We ust all of us submit to the test of most stringent persona examination the doctrines of pathology and treatment which we propose to act on in our own practice. And we must all remember that ou $\eta^{*}$ conclusions will in turn be criticized; that a later generation, standing on a basis of a wider knowledge, will perhaps condemn us too; and that we had need remember with humility the words of our great poet:-

$$
\begin{gathered}
\text { "Our little systems have their day- } \\
\text { They have their day, and cease to be; } \\
\text { They are but broken lights of thee-" } \\
\text { And thou, o Lord, art more than they." }
\end{gathered}
$$

\section{ON HYDATIDIFORM OVUM.}

BY GRAILY HEWITT, M.D., M.R.C.P.,

PHTSTCTAN TO THE BRTTISH LYING-IN HOSPITAL, LECTURER ON MTDWIFERY AND DISEASES OF WOMEN AND CHILDREIT AT ST. MARY'S FOSPITAL,

THE following case deserves record as an interesting contribution to the history and symptomatology of that not very common pathological condition-hydatidiform degeneration of the ovum.

On August 18th last I was requested to visit, in consultation with the gentleman in attendance, a lady who presented symp. toms of abortion. The history of the case may be summed up very briefly. The patient, aged twenty-eight, who had been married exactly three months, was last "unwell" the week previous to her marriage. Three weeks ago, while ont for a walk, she experienced a slight strain in getting over a stile, and dating from that time there has been a slight "show." During the last fortnight she has been seen at intervals, and appropriately treated as for an impending miscarriage. The night preceding my visit, a severe flooding suddenly occurred at midnight, to restrain which the gentleman in attendance had plugged the vagina. The plug had been removed an hour previous to my visit (seven A.M.), and no further hæmorrhage had occurred. On examining the abdomen, I was struck by its great size; there was a tumour, evidently the enlarged aterus, reaching to two inches above the umbilicus. The first impression produced on my mind was that the pregnancy must have advanced much further than the time stated-three months. On examining per vaginam, the os was found open, and just within it was felt a sott, smooth substance, occupying the lower part of the cavity, and having the feel of a placenta. The index finger passed readily round within the os, between the mass in question and the uterine wall. The case appeared at this stage of the inquiry to be one of placenta prævia. A further careful examination of the abdomen by the stethoscope and by palpation was instituted, and the patient cross examined as to the history of the case, no opinion of course being expressed. The account given was again the same. No fotal heart-beat could be detected, but a murmur, like the placental souffle, was audible in the left groin. The nterine tumour was hard, firm, and resistant.

The physical appearances and the history of the case each pointed to a different conclusion as regarded the diagnosis. I determined, however, to introduce the hand into the vaginathe fingers only having been previously used-and to deliver the child, which I expected to find in the uterus, by turning, should that course be sanctioned by the results of further ex amination. With no great difficulty this was accomplished, but on passing the fingers into the uterus no presenting part could be anywhere discovered. Everywhere a soft, slightly resisting mass was felt, traversed by what appeared to be fibrous bands $_{x}$ The failure to find any fotus in the uterus, coupled with the sensation conveyed by the touch, at once indicated to me the nature of the case. The aterus was evidently filled with an hydatidiform ovum, and I forthwith drew from its cavity a mass of the product in question sufficient to half fill an ordinary washhand basin. Mixed up with the vesicular bodies and their fibrous pedicles and stalks, were some flattened non-recent coagula; some of the vesicles were an inch in diameter. The structure was precisely similar to that presented in other analogous cases. No further hamorrhage followed the emptying of the uterus, and the patient made a good recovery.

Remarks. - The case presents facts both interesting and in. structive. One or two only of these I will allude to. As regards the origin and cause of the degeneration of the ovum in this case, it may be set down to the "strain" experienced by the patient three weeks previous. The fotus (no trace of which, by-the-bye, was discoverable in the mass expelled) doubtless perished at that time, but the separation of the ovum from the uterus, though sufficient to kill the embryo, was not complete, and the chorion villi continued to grow by absorption from the lining of the uterus, the result being as above described. The facts of the case are quite in accordance with the theory of the nature of this curious pathological product I have elsewhere* fully elaborated, and which I need not therefore discuss here.

Clinically, the rapidity of the growth of the abnormal product in this case is interesting, and, in fact, this led to some perplexity in the matter of the diagnosis. In three weeks after the presumed commencement of the growth of the morbid pro. duct in question, the uterus had attained the size of that of a woman at least seven months pregnant. Rapid growth in the size of the uterus is well known to be one of the symptoms of the condition actually present; but in no previously recorded case has the uterus attained such a size as that above described at such an early period as three months after the commencement of the pregnancy. The nearest approach to it is a case related by Drs. Hardy and $\mathrm{M}^{\prime}$ Clintock, where the woman was four months pregnant, and the uterus had attained the size of six months.

Dr. Montgomery, in reference to the diagnosis of these cases, says: "We have no satisfactory grounds on which to form an opinion in the way of diagnosis beyond this, that if a woman after experiencing the ordinary symptoms of pregnancy up to the third or fourth month is observed to be growing large with rapidity, so that her size corresponds to a period much more advanced than her pregnancy really is, or is supposed to be," ...\&c. This proposition is well borne out by the facts of the case now related: up to the end of the second month matters proceeded regularly. The period at which the change may com. mence is, $I$ believe, strictly limited to that interval of time during which the chorion villi are in one particular stage of development-from a short time before to a short time after the end of the second month. After the transformation of the villi into vessels has been effected, the production of the hyda. tidiform ovum is no longer possible.

Berkeley-square, Sept. 1862.

\section{SURGICAL NOTES.}

\section{BY JOHN ROSE, A.M., M.D., Surgeon R.N.}

\section{ABSCESS OF BRAIN.}

Trre case of abscess of the brain recorded by Dr. A. L. Adams in the present volume of THE LANCET, p. 34, remiads me of the following, which occurred in the practice of the late Dr. Lindsay, Inspector. General R.N.:-

The patient, aged forty-three, private Royal Marines, was admitted into Haslar Hospital on the 2lst July, 1853. He had been placed on the sick-list on board his ship on the 9 th May with a tumour on the occiput. The tumour was opened, and the bone found denuded to some extent of its periosteum. The wound had been kept patent by enlarging the opening from time to time as required. Iodide of potassium and compound decoction of sarsaparilla had been administered, and nitrate of silver applied to the wound.

On admission, at half-past eleven A.M., he appeared to be in a weak and delicate state of health; but there were no particular symptoms present, and nothing to indicate immediate death. The sore on scalp looking foul, a linseed poultice was applied. At midnight he was attacked with retching, and the surface and extremities became cold, with a feeble pulse. * Obstetrical Iransactions, vols, $i$ and ii 